\title{
DE BOLIVIA A BUENOS AIRES Y DEL PREMIO AL PLAGIO: MIGRACIÓN Y NOVELA EN LA OBRA DE 'BRUNO MORALES'
}

\author{
POR \\ DieTER INGENSChAY \\ Humboldt-Universität zu Berlin
}

INTRODUCCIÓN: DEL PLAGIO AL ÉXITO O HACIA UNA NUEVA CONCEPCIÓN DE LA LITERATURA

Entre el gran número de casos de supuesto o probado plagio, el "caso Bruno Morales" ha ganado una dinámica propia y un carácter específico. Conviene recordar algunos datos básicos: en 2006 el periodista, traductor y escritor argentino Sergio Di Nucci publica, bajo el seudónimo (que suena tan "boliviano") de Bruno Morales, el libro Bolivia Construcciones, una especie de novela que cuenta en 87 fragmentos, la historia (o mejor: algunas historias) de dos inmigrantes bolivianos en la Argentina actual: su llegada, su vida, sus problemas. Se trata de un texto interesante tanto por su forma como por su estilo y su explícita imparcialidad (porque apenas denuncia el mal trato de los bolivianos y bolivianas en el mercado laboral argentino y casi no menciona la explotación de los trabajadores inmigrados).

El jurado del importante Premio "La Nación /Sudamericana", compuesto por intelectuales tan destacados como Carlos Fuentes, Griselda Gambarro y Tomás Eloy Martínez, decidió otorgar el premio de 2006 al libro de Bruno Morales. El autor, por su parte, cuando recibió el dinero del premio, lo transfirió a ADA, una organización boliviana no gubernamental, poco antes de que un lector de 19 años denunciara, en una carta dirigida al periódico Página 12, que en el texto de Bruno Morales se encuentran unas 30 páginas que corresponden casi literalmente a una parte de $N a d a$, ejemplo ya clásico del género de la novela tremendista, de la española Carmen Laforet, publicada en 1944.

Acto seguido, la comisión revocó su decisión y la editorial detuvo la entrega de las copias no distribuidas. El autor Sergio Di Nucci, por su parte, puso el texto íntegro en la red de libre acceso y manifestó su sorpresa frente al reproche de plagio. Por cierto, argumentó, que si el ilustre jurado ya conocía aquella novela prolífica se deberían haber dado cuenta de su forma de "citarla", modificando por completo el contexto. Además, añade el escritor incriminado, "no hay una sola oración que no aluda a otro 
texto" (cita en la entrevista a Cecilia Boullosa, Revista N). Parte del público crítico comentó con regodeo esta prueba de la gran farándula de los premios literarios, entre ellos el escritor argentino Washington Cucurto: "ésta es una idea genial para vender un libro y crear un pequeño escándalo en el mundillo literario. Sonreí por la travesura", (Cucurto, “¿Ha vuelto Bruno Morales?”). Entre las reacciones divergentes destaca la posición de Claudio Zeiger, novelista y periodista (de Página 12) quien explica:

No era un caso de plagio patológico [...] ni de un simple escriba desesperado que, para completar a contrarreloj su obra a ser presentada en el concurso, le anexa unas cuantas páginas ajenas disimulando como puede el delito textual. Aquí no. En el uso del seudónimo - combinado con la creación de un heterónimo, ya que Bruno Morales se presenta como escritor-y en el título de la obra, empezaba a insinuarse -y señalizarse a su manera- la diferencia. Se trataba de una "operación literaria", una combinación de teoría y práctica de la literatura, una intención deliberada, un ensamble de ficción y metaficción. Tras la fachada de un texto absolutamente legible y transparente que devolvía en su espejo sin mácula la mirada emocionada y contenida sobre los avatares de migrantes bolivianos en Argentina, se escondía algo más complejo, con citas ocultas, intertextualidad y otras prácticas que -destapada la olla- hicieron las delicias de una crítica que para proteger a Di Nucci contra ataques bastante obtusos por cierto, lo defendían por lo que había hecho y no por lo que no había hecho. (Zeiger, "The Bolivia Affair")

Mientras que una parte de la crítica apoyó a la editorial en su decisión de suspender la distribución del texto, los defensores de Di Nucci juntaron firmas y escribieron largas cartas apologéticas, entre ellas la llamada "Carta de Puán" (con referencia a la sede del programa postdoctoral de la Universidad de Buenos Aires), en las que explicaban la aparición de una nueva era bajo viejas condiciones. Graciela Speranza fraguó el término de "micropiratería" (Speranza), Daniel Link se dirigió a dimensiones bíblicas ("A César lo que es de César") y Susana Santos resumió en su blog: "La literatura no hace declaraciones de aduana" (en "La literatura interrumpida") e incriminó al grupo de los detractores de una posición fascistoide: "Que la literatura produzca efectos sociales y ella misma sea un efecto social, es una verdad de perogrullo. Pero que los críticos literarios reclamen más y mayor control social sobre ella, hace resonar ecos fascistoides" (Susana Santos, "Literatura interrumpida"). El artículo de Lucienne Azevedo ofrece un excelente resumen de las diferentes posiciones desde ambas perspectivas (Azevedo). Sergio Di Nucci mismo, quizás también para probar su competencia como escritor, se ocupó de nuevo con la misma temática y escribió una especie de segunda parte, Grandeza boliviana, un texto enteramente suyo, publicado en 2010 por la editorial Eterna cadencia. El texto no sigue la pista intertextual implícita del título (con su alusión a la Grandeza mexicana de Bernardo de Balbuena de 1604), sino vuelve a los dos personajes principales de Bolivia Construcciones, sus problemas, sus ideas, y al

Revista Iberoamericana, Vol. LXXXI, Núm. 253, Octubre-Diciembre 2015, 1065-1076 
mismo estilo fragmentario que es, para él, el elemento de una escritura diferente. Cabe añadir que su tercera novela, escrita en cooperación con Alfredo Grieco, fue publicada bajo el pseudónimo de Andrés Arbiau en 2012 y se llama Plato Paceño.

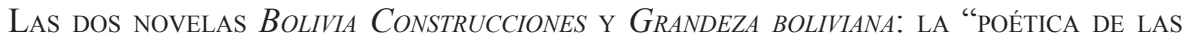
MINUCIAS"

Ambas novelas se constituyen según un mismo patrón: están compuestas por fragmentos caracterizados por un estilo simple, a veces coloquial, objetivo y personal a la vez. Al inicio, en los primeros fragmentos de Bolivia Construcciones, el relato parece cronológico: empieza contando el viaje del protagonista de Bolivia a la Argentina, pasando la frontera entre la ciudad boliviana de Villazón y La Quiaca, estación fronteriza argentina en el Departamento de Yavi, Provincia de Jujuy, un paso común para muchísimos de los migrantes bolivianos y para los turistas que se dirigen hacia el sur.

Para el protagonista, narrador en primera persona en aquellas partes de la novela que no están formadas por diálogos, la experiencia de la frontera es, a la vez, un primer contacto con una cultura diferente y otra variante del castellano:

Un suboficial argentino, barrigón, de ojos vivaces, más bien petiso y morocho, con la camisa desabrochada y aliento a vino, me preguntó cosas que no supe responder. Adelantaba el cuello, como si quisiera husmear una fuente de asado que un oficial le sacaba de la mesa y nunca le dejaba oler.

- Y decime, ¿por qué venís a la Argentina?

Me sorprendió el voseo y sentí ganas de decirle, para confirmar sus sospechas, "a vender setenta y dos kilos de pasta base chucha-tu-madre", recordando el célebre insulto peruano. Pero cordialmente le dije:

- A visitar a mi madre.

Quispe me felicitó por cómo me había comportado. (Fragm. 1)

El personaje principal, que no tiene nombre, es un joven de menos de 21 años (como se da a conocer en el fragmento 87, el último, donde él decide independizarse), viaja con su tío llamado el Quispe (palabra quechua que significa ‘vidrio’), que lo acompaña a través de sus quehaceres en la Argentina y quien a lo largo del relato de los fragmentos busca y encuentra trabajos de albañilería para ambos, trabajan al servicio de Pedro, dueño intelectual y amigo argentino proveniente de Sucre. Con Quispe, el narrador también comparte la pensión donde se aloja así como gran parte de su tiempo libre en la capital argentina, y es él quien le explica a su sobrino cómo funciona la Argentina:

En el camino desde el barrio, muchas veces, el Quispe me explicaba la Argentina.

- Es más interesante que las vírgenes del Altiplano, y más exagerado.

Revista Iberoamericana, Vol. LXXXI, Núm. 253, Octubre-Diciembre 2015, 1065-1076 ISSN 0034-9631 (Impreso) 
$[\ldots]$

Después sabía que en la Argentina había fascistas, y hasta neonazis. Siempre aparecían por televisión. A la gente le interesaba mucho. [...] (Fragm. 8)

Así, el contraste entre las formas de vida en Potosí, su región de origen, y en la Ciudad Autónoma de Buenos Aires se tematiza muchas veces y justifica considerar la diferencia cultural como tema principal del texto (más que la denuncia de la explotación de los obreros extranjeros en la zona porteña por ejemplo). A primera vista, esta diferencia se concibe y describe desde la perspectiva boliviana (elegida a propósito por el autor argentino) e implica a veces cierta (auto)crítica irónica, por ejemplo:

Argentina es ingrata con los migrantes y todavía más con los bolivianos. Pero Argentina, como las mujeres, fue hecha para ser querida y no para comprenderla (Fragm. 6)

Junto al lenguaje, el tema de la comida concretiza las diferencias experimentadas por el narrador y sus compatriotas. A pesar de la buena reputación de la que goza la cocina argentina en Europa, a los migrantes les parece aburrida e insípida, prefieren la cocina boliviana y constatan que los mejores platos son los peruanos.

Una vez llegados a la Capital Federal, el mismo Quispe tiene problemas para orientarse y encontrar el transporte hacia la pensión de Doña Estefanía donde van a alojarse. Ella es la dueña de una modesta casa de huéspedes que recibe a bolivianos, parece boliviana, pero no lo es, ya que nació en Mar del Plata y en realidad se llama Marcela.

Su pensión está situada en la calle Bonorino, entre el Cementerio de San José de Flores y la famosa calle Rivadavia, la más extendida de la capital (con más de $30 \mathrm{~km}$ dentro del distrito urbano), en aquella parte del barrio popular de Flores que se llama Bajo Flores, barrio conocido por sus inmigrantes paraguayos, bolivianos y coreanos y en parte compuesto de chabolas, las llamadas villas miseria (el mismo barrio tiene un papel central en La villa, novela de César Aira sobre la vida en una villa miseria). A pesar de su mala fama, la calle Bonorino con su oferta de puestos de comida boliviana y peruana se vuelve rápidamente su segunda patria para el protagonista.

Nos fuimos para la avenida Bonorino. Estaba cerca. Cerca del punto de partida. Había puestos de comida boliviana, y también de comida peruana, enfrentados en torno a puestos con frutas y verduras, autos destartalados que sin embargo se movían y gente ebria, solos o en grupo. [...]

Yo estaba impresionado por la cantidad de objetos que encontraba. Casillas apretadas, unas junto a otras, por encima y al costado, pasillos angostos que de pronto terminaban, bares y pequeños comedores, carteles mal pintados, almacenes que vendían desde harina hasta bicicletas y el color abigarrado de las parrillas y los olores me recordaron

Revista Iberoamericana, Vol. LXXXI, Núm. 253, Octubre-Diciembre 2015, 1065-1076 
otra vez La Paz pero también ciertas zonas de Potosí. Era también confusa la música que salía de los departamentos [...]. (Fragm. 6)

Como se ve en la cita, no se describe, sino más bien se suprime la extrema miseria de esta misma zona.

Es esta misma parte de la geografía urbana bonaerense que describe la que había entrado en la consideración pública en la época de la famosa crisis argentina (alrededor de 2003). Así se lee la descripción de Bajo Flores de la pluma de Beatríz Sarlo en su libro La ciudad vista: "La basura cubre las calles, flota en el aire, se amontona en los rincones. [...] Estamos en el sur de la ciudad, la zona discriminada." (123). Y Sarlo afirma que se trata de una zona que produce "vergüenza", "donde cualquier pasillo se va angostando hacia adentro como si lo de afuera consistiera en el revestimiento de ladrillos de un interior fangoso y oscuro, con casillas entremezcladas cuyas paredes nunca son completamente verticales" (126).

De hecho, en la novela de Bruno Morales, la casa de Doña Estefanía dispone de una "ampliación", donde se encuentra el baño y que rebosa de arañas y cucarachas, pero, con esta excepción, el texto renuncia a más descripciones negativas de la notoria villa 1-11-14, y la transforma, como dije antes, en el hogar, en la patria del joven inmigrante.

La elección de esta zona, tanto como los caminos interurbanos de los protagonistas, muestran que el autor es conocedor de la geografía urbana de la ciudad porteña; las descripciones o sobre todo la evocación del ambiente de ciertos barrios vuelve a menudo a lo largo del texto, mucho más de lo necesario, cuando pasan por zonas céntricas como Retiro, la plaza y las calles de Once, centro de la inmigración desde siempre, o cuando van a trabajar a zonas suburbanas como Laferrere.

Bajo Flores es el típico barrio de inmigrantes. La fuerte presencia de peruanos y bolivianos se nota desde el inicio de los fragmentos, cuando el narrador entra en una tienda con el Quispe y el cartel indica "Urkupiña", aludiendo a la Virgen de Urkupiña, venerada sobre todo en la provincia de Cochabamba y que se ha convertido en una figura emblemática de los emigrantes bolivianos. Así como la Virgen de Guadalupe es el emblema de la migración mexicana en EE.UU., como Silvia Spitta lo ha demostrado de forma magistral ("La Virgen"), Virgen omnipresente, en movimiento, adorno de buses y autos mexicanos, la Virgen de Urkupiña adopta la misma función para los bolivianos. La radio boliviana de Buenos Aires (AM 1550), por ejemplo, se llama Radio Urkupiña en honor de la Virgen. Cuando el narrador tiene, hacia el final del texto, una relación con una chica rubia de la misma pensión, Sylvia, la compara por su belleza con la misma Virgen de Urkupiña.

Se cuenta un poco de los trabajos que hacen -se trata de trabajos de construcción, una chimenea en una casa particular de gente de clase media, otra tarea para un fabricante de pasta de origen italiano etc. Se tematiza la construcción de nuevos 'monobloques', realizada por compañías anónimas y que hacen grandes promesas a los eventuales

Revista Iberoamericana, Vol. LXXXI, Núm. 253, Octubre-Diciembre 2015, 1065-1076 ISSN 0034-9631 (Impreso) 
compradores y se cuentan contactos con extranjeros (un alemán, unas mujeres de Europa del Este). A menudo se hace palpable el complejo de inferioridad que tienen los bolivianos frente a los argentinos: "Siempre nos discriminamos -saltó el QuispeNo hay cardenal boliviano. Tampoco Premio Nobel." (Fragm. 18)

Se mencionan, en passant, temas como el efecto invernadero o los efectos de la coca y de la cocaína, y se encuentran algunas alusiones al mundo literario (con la mención de un tal Bruno Morales como gran prosista al final del fragmento 33 a modo de mise en abyme). El tema principal de la narración, sin embargo, parece ser la diferencia entre la cultura de los inmigrantes y la cultura receptora misma.

Al día siguiente, todos querían matar a los peruanos que habían disparado. La gente se paraba para decírselo a los vecinos.

- Los bolivianos son distintos de los argentinos. El argentino es un furioso nato. Lo que se ve, por la calle, son indignados de ambos sexos. Pero cuando los bolivianos se enojan, queman vivo a un alcalde -explicaba el Quispe. (Fragm. 35)

Este supuesto carácter propio de los bolivianos en comparación con el supuesto argentino reaparece a menudo, por ejemplo, en el divertido diálogo que tienen los albañiles con el chico burgués, universitario e izquierdista, hijo de la dueña de una casa en la que hacen obras. En cuanto al estilo, en resumidas cuentas, propongo hablar de una "poética de las minucias" (Poetik der Belanglosigkeit) que caracteriza tanto a la primera novela como a la segunda, Grandeza boliviana. En lugar de exponer en detalle el contenido de la segunda novela, cito una descripción muy precisa de la misma de Claudio Zeiger:

Grandeza boliviana se instala cómodamente en el terreno de Bolivia construcciones en cuanto al lenguaje y los procedimientos de su estructura. Muy trabajado para lograr una sencillez de expresión que se apoya en capítulos breves y estilizados a la manera de un elegante minimalismo, el relato avanza tenue, como una picaresca de contenido humor. La mirada del narrador se vuelve híper atenta mientras se hace el distraído, parece que a cada paso va a descubrir el mundo, un mundo que no se le termina de revelar del todo. En esa indecisión, en ese desajuste entre el mundo y la mirada del mundo está lo mejor de Grandeza boliviana. Y, una vez más, en esa sensibilidad que el autor logra comprimir en una pena infinita que emite brillos desde el fondo de una humillación no dicha, dignamente rodeada de silencio. Una pena que no se permite hablar más de la cuenta. Si hay algo que objetar aquí es cierto hermetismo a causa de la acumulación de enigmas que no se resuelven, hasta encriptar la lectura. Si bien se entiende que la intención es trabajar más en profundidad la "problemática" de la comunidad boliviana en Argentina que en la novela anterior, las huellas se van desdibujando a medida que avanza la lectura. (Zeiger, "The Bolivia Affair")

Revista Iberoamericana, Vol. LXXXI, Núm. 253, Octubre-Diciembre 2015, 1065-1076 


\section{Migración y CONTACTO SOCiO-CUltural En las nOvelas De Bruno Morales}

La migración boliviana a Argentina no es nada muy nuevo. La primera ola de inmigrantes bolivianos llegó alrededor de 1930, durante y después de la guerra del Chaco. Sin embargo, las cifras se multiplicaron en los últimos treinta años, bajo el signo de una globalización en crecimiento (para más detalles ver Pacecca/Courtis). El censo indica que desde el año 2010, 345.272 personas de nacionalidad boliviana residen en la República Argentina, siendo este grupo el segundo (después de los paraguayos). La cifra verdadera, se supone, podría ser tres veces más alta, de más de un millón, lo que correspondería a unos $2,5 \%$ de la población total de la Argentina, dado que prácticamente a partir de 1983 llegó de manera permanente un gran número de bolivianos. Los inmigrantes bolivianos trabajan en el cultivo y venta de frutas y verduras, y gran número de mujeres trabajan en la industria de ropa y calzado (ver Alfaro Aramayo). Se supone que sólo en Buenos Aires, unas 100.000 bolivianas trabajan en talleres secretos de ropa, abiertos en 1990 como reacción contra las importaciones baratas de Asia. (Bolivia Construcciones alude en el fragmento 32 a las trabajadoras en el sector de la industria textil, sin profundizar en el tema.) Argentina es, desde la otra perspectiva, el país de destino número uno de los bolivianos. Desde 2003 las leyes de inmigración aprobadas por la administración de Néstor Kirchner facilitan obtener un permiso de residencia, aunque la cifra de los "sin papeles" sigue siendo elevado; el llamado proceso de "radicación" se tematiza en el fragmento no. 40 de la novela:

- Ahora los trámites de radicación son más fáciles -se le ocurrió decir a Augusto.

Al Quispe y Pedro no les importaba nada; solamente estaban interesados en decir que no siempre había sido así.

- La primera vez que tuve que hacerlo, fui a un edificio moderno con muchas puertas que se abren para dejar pasar a hombres grandes con bigotes finitos y hombres jóvenes con cejas que parecen postizas, quienes se dicen unos a otros: "Esto me huele a menemismo". Después de hacer horas de cola, me mandaron a una ventanilla donde había una empleada, que hojeaba mis papeles mientras duró este diálogo:

- ¿Para cuándo quiere su radicación?

- Lo más rápido posible, claro, para quedarme, que ya estoy acá.

- No va a poder ser. Se va a tener que volver. Tenemos que ponernos en contacto con nuestro representante en Bolivia, para que nos diga si en su caso es necesario un fiador [...] (Fragm. 40)

Algunas iniciativas de ciudadanos han intentado llamar la atención sobre la situación más que precaria de los bolivianos y de las bolivianas en Argentina, pero resulta difícil encontrar medidas efectivas para mejorar o cambiar su situación. Entre las manifestaciones políticas (tan frecuentes en Buenos Aires), hay algunas tanto a favor de los inmigrantes como otras en contra, en este último caso respaldadas por cierta parte

Revista Iberoamericana, Vol. LXXXI, Núm. 253, Octubre-Diciembre 2015, 1065-1076 
de la población porteña que quiere excluir a los bolivianos, ecuatorianos y peruanos, y, a la vez, a los compatriotas de las periferias, como del Chaco por ejemplo. El autor conoce la situación, dado que Sergio Di Nucci es periodista y bonaerense. Su primer viaje a Bolivia lo hizo en 1993. En 2005 publicó en el periódico Vocero Boliviano la historia personal de un inmigrante boliviano proveniente de Potosí que se puede considerar como la base de la novela posterior, de forma que podríamos considerar el procedimiento literario que llevó a las dos novelas como una nueva forma de la literatura testimonial (en el sentido de Miguel Barnet y de Elisabeth Burgos). No voy a ahondar en este aspecto, sino, dentro de este contexto, en el de los aspectos "transandinos" de las novelas bolivianas de Bruno Morales/Sergio Di Nucci.

\section{DISCURSO TRANSANDINO, MIGRACIÓN Y ESTUDIOS REGIONALES}

El concepto de una cultura transandina pregunta, para citar el programa que Marco Bosshard propuso en su invitación al simposio internacional Estudios Transandinos, “Cómo se modela, (re-)construye y vive este espacio cultural, ya no reducido a las fronteras nacionales, en las lenguas, literaturas, artes y prácticas culturales cotidianas?”. Llama la atención que esta noción o este concepto de lo "transandino" difiere del uso clásico del término en Chile y en la Argentina. En ambos países sirve para denominar la cultura/literatura del otro país "trasandino", respectivamente, es decir que para hablar de la literatura chilena, los argentinos usan esta palabra y viceversa. Y además, trenes y compañías comerciales también suelen ser transandinos a veces.

Cuando se trata de reajustar el término como concepto transnacional en el contexto hoy día determinado como "estudios regionales", se impone, desde la perspectiva de la crítica literario-cultural actual, recurrir a un conjunto de conceptos de las literaturas "trans", descritas primero como culturas "nómadas" con el término que Gilles Deleuze fraguó en 1972. Después se precisaron como "literaturas sin residencia fija” (por Ottmar Ette) o de literaturas desplazadas (descritas, entre otros, por Fernando de Toro), para nombrar dos ejemplos destacados entre la abundante crítica literaria que existe sobre el fenómeno de las llamadas literaturas de migración (y baste apuntar a una corta lista de títulos pertinentes que no voy a enumerar ahora, desde Hans-Ludwig Arnold, Klaus-Dieter Ertler hasta Irene Andres-Suárez y Roy Sommer).

Múltiples son las relaciones entre las "ocho (intro)specciones" que Ottmar Ette propone en ZwischenWeltenSchreiben. Literaturen ohne festen Wohnsitz y las novelas de Bruno Morales: tenemos que ver con un planeta bajo el signo de la migración, $\mathrm{y}$ con discursos que operan de forma significativa con vectores transnacionales, es decir con los movimientos entre el Perú, Bolivia y la Argentina, y transareales, dado que los flujos migratorios también incluyen a argentinos del Chaco u otras regiones periféricas hacia la capital, un hecho muy conocido. Sin embargo, en las dos novelas 'bolivianas' que trato, faltan los aspectos transgeneracionales y transtemporales que caracterizan

Revista Iberoamericana, Vol. LXXXI, Núm. 253, Octubre-Diciembre 2015, 1065-1076 
los ejemplos de Ette, las impresionantes novelas de Cécile Wajsbrot y de Sherko Fatah. Tenemos que ver con textos mucho más modestos en cuanto a sus pretensiones literarias. En los ejemplos del octavo capítulo de su libro, Ottmar Ette nos los presenta como una escritura sin patria (heimatlos), marcada por la experiencia del pasado, situada en un entre-mundo (del aquí y allá) y, en resumidas cuentas, como una escritura "después de la migración". Las literaturas "sin residencia fija", para Ottmar Ette, comprenden tanto la literatura del exilio, de la Shoa, de migración como la literatura de viajes en general, un conjunto dedicado en su totalidad al movimiento transareal.

En contraste, podríamos considerar a Bolivia Construcciones y a Grandeza boliviana como novelas sobre el proceso actual de la migración misma, que no tematizan el gran horizonte de la experiencia traumatizante ni la inminente pérdida de la vida, sino las modestas prácticas de supervivencia en un mundo diferente, descrito por un autor familiarizado con la sociedad argentina y que, en el fondo, la critica o le pone el espejo en la cara. ${ }^{1}$ De hecho, tengo que recordar que las dos novelas presentadas fueron escritas por un bonaerense, y que la acción tiene lugar en la capital federal, aunque en un ámbito particular no común. Por ende, no se trata de un autor "con fondo migratorio", y sería erróneo etiquetarlas como literatura de migración (cuando se limita el término a textos literarios que son productos de la experiencia vivida por su autor).

En su ensayo "El desplazamiento de la literatura y las literaturas del desplazamiento", Fernando de Toro despliega, basándose en los trabajos de Said, Bhabha y muchos otros, el papel de los procesos de desplazamiento en las culturas actuales, tomando como ejemplos literarios, entre otras, novelas de Carlos Fuentes, Nicole Brossard, Salman Rushdie o Michel Ondaatje, textos que abren una dimensión que va más allá de las identidades nacionales clásicas, que se constituyen en condiciones globales y que reflejan los múltiples procesos migratorios (ver De Toro, "Desplazamiento"). Tematizan a menudo -sirva Ondaatje de prueba- experiencias transnacionales como tortura, genocidio, brutalidad política y militar, temas por completo ausentes en los textos que acabo de presentar que por ende tampoco caben en la categoría de las literaturas del desplazamiento tal y como De Toro las concibe.

Regresemos adfontes: el inicio de las teorías nomadológicas es, como se sabe, "La pensée nomade" que Deleuze escribió en 1972 y publicó en 1973. El hecho de elegir la noción de lo nómade como piedra angular de su complejo modelo geofilosófico muestra la importancia y el papel central del concepto mismo. En la introducción del Tratado de Nomadología, parte del volumen Mil mesetas, Deleuze y Guattari apuntan a Aquiles y Pentesilea en la obra de Kleist, y a dos juegos que pueden ilustrar la máquina de la guerra en la que los personajes centrales se comprometen: ajedrez y go

Para una crítica similar sobre Bolivia Construcciones, ver la colaboriación de Meritxell Hernando Marsal en este volumen.

Revista Iberoamericana, Vol. LXXXI, Núm. 253, Octubre-Diciembre 2015, $1065-1076$ ISSN 0034-9631 (Impreso) 
(Deleuze/Guattari 1988). Mientras que Aquiles sigue el juego del Estado (o de la guerra institucionalizada), lo que corresponde al modus operandi del ajedrez, Pentesilea y las amazonas descubren la táctica del go, de una guerra sin líneas de batalla. Proyectando la metáfora central deleuziana a Bruno Morales, la sociedad receptora argentina con sus reglamentos estatales sería jugadora de ajedrez, mientras que la comunidad híbrida, polifacética y versátil de los inmigrantes correspondería a los jugadores del go. Este modelo nos daría, de forma convincente, una respuesta a la pregunta tradicional de la representación y de la autonomía del subalterno en el discurso literario "trans", un problema al que vuelve una crítica reciente que introduce al análisis la categoría de lo "transdiferente" (o de la "transdiferencia") para combinar las polipertinencias [Mehrfachzugehörigkeiten] con las contradicciones "identitarias" tan características del discurso migratorio actual (ver Kalscheuer y Allolio-Näcke).

\section{LAS DIMENSIONES DE UNA NUEVA LITERATURA}

Ambas novelas "transdiferentes" y "transandinas" de Bruno Morales enfocan el tema de la inmigración boliviana. Sin embargo, no son novelas de migración, porque su autor no es un autor de migración ni con residencia desplazada, es un argentino que se apropia del tema de la migración, entre otros, para condenar la altivez y la xenofobia de las regiones más desarrolladas. Como producto lateral ayuda a una remodelación de la literatura actual que, en este caso, incluye la creación de un discurso transandino. En ÜberLebensWissen, Ottmar Ette plantea que la llamada literatura de migración es una parte integral de las literaturas nacionales (242); lo que vale sin duda para las novelas de Bruno Morales. Pero el carácter transdiferente y transandino añade aspectos decisivos que a la vez rompen los moldes prevalentes en la narración argentina actual.

Desde mi perspectiva, uno de los rasgos decisivos de las dos novelas presentadas es su cercanía a la literatura urbana que tantas veces, desde Dos Passos, Joyce, Döblin y Cela, inspiró nuevos derroteros para la escritura de un momento determinado. Pero va más allá y se diferencia de la novela urbana clásica, porque abarca más aspectos de la migración que Berlin Alexanderplatz (donde, por cierto, migrantes polacos y judíos tienen su papel preciso). ${ }^{2}$ En el caso de Bruno Morales, la combinación de lo urbano con la experiencia migratoria lleva a renunciar a la organización clásica de un relato determinado en el tiempo y en un espacio urbano semiotizado. No es insignificante que Josefina Ludmer tomara el texto de Bolivia Construcciones como un ejemplo de un tipo novedoso de novela: "(n)o se sabe o no importa si son o no son literatura. Y tampoco se sabe si son realidad o ficción. Se instalan localmente y en una realidad

2 Para un estudio de caso de una novela de esta índole en el espacio andino, con énfasis en los desplazamientos migratorios del campo a la ciudad marcados por el tratamiento de la música, ver la colaboración de Jorge Coronado en este volumen.

Revista Iberoamericana, Vol. LXXXI, Núm. 253, Octubre-Diciembre 2015, 1065-1076 
cotidiana para 'fabricar presente' y ése es precisamente su sentido" (Ludmer, "Literaturas postautónomas"). A este nuevo tipo de relatos la crítica argentina le pega la etiqueta de "literatura postautónoma", porque "(re)presentarían a la literatura en el fin del ciclo de la autonomía literaria, en la época de las empresas transnacionales del libro o de las oficinas del libro en las grandes cadenas de diarios, radios, TV y otros medios".

Estoy de acuerdo con Josefina Ludmer que, en su categorización de textos 'postautónomos' como Bolivia Construcciones, La Villa de César Aira o Montserrat de Daniel Link, destaca la función de la experiencia de la realidad cotidiana en una "isla urbana" o un "territorio local". Por otra parte, la crítica argentina con su cátedra en Yale insiste en el papel que ocupa el tema de la migración en estos mismos textos, cuando menciona 'las experiencias de la migración y del 'subsuelo' de ciertos sujetos que se definen afuera y adentro de ciertos territorios".

El aspecto del fin de la autonomía literaria puede servir para entender aquella nueva concepción de una literatura que se descabalga de la noción de plagio, tal y como Bruno Morales lo postula y sus defensores lo confirman. Pero hay aspectos no menos pertinentes que podemos extraer de la discusión de los textos presentados. Estos aspectos resultan de un nuevo trato de la temática urbana, de una nueva visión del espacio de la ciudad tal y como la población migratoria la percibe, con nuevos centros, otras jerarquías y problemas diferentes, inusuales, y con nuevos símbolos y emblemas identidarios (como la Virgen de Urkipiña). Los "bajos fondos" de la metrópolis ya no son el almacén temático de los misterios y escándalos, sino que representan la vida cotidiana. A esto se une un lenguaje literario fuera de lo tradicional y que pone en tela de juicio las propiedades lingüísticas de las variantes del español sudamericano. Como textos transdiferentes, suspenden la lógica binaria entre los dos países centrales del discurso. Desde la perspectiva transandina, son novelas que rechazan la superioridad de un centro potente para celebrar la diversidad rizomática. Es un efecto colateral que apoya a la vez el proceso de emancipación de la población inmigrada.

\section{BiBLIOGRAFíA}

Alfaro Aramayo, Yolanda. Trayectoria de los estudios migratorios en Bolivia. Quito: FLACSO, 2009.

Azevedo, Lucienne. "Pirataria literaria tem valor?". ABEHACHE. Revista de la asociación brasileña de hispanistas 1/1-2 (2011): 43-58.

Boullosa, Cecilia. "Sergio Di Nucci: "No hay una sola oración que no aluda a otro texto"”. N. Revista de cultura. 11 mayo 2010, s.p. $<$ http://edant.revistaenie.clarin. com/notas/2010/05/11/_-02194158.htm>. 1 ago. 2014.

Cucurto, Washington. “¿Ha vuelto Bruno Morales?” 'Bruno Morales’ Blog de la editorial Eterna Cadencia. 18 marzo 2010. <http://blog.eternacadencia.com.ar/ archives/tag/bruno-morales>. 1 ago. 2014.

Revista Iberoamericana, Vol. LXXXI, Núm. 253, Octubre-Diciembre 2015, 1065-1076 
Deleuze, Gilles. "La pensée nomade". Nietzsche-aujourd'hui? Coll. de Cérisy-la-Salle, Paris: Union Générale d'Editions, 1973. 159-74.

y Félix Guattari. Mil Mesetas. Capitalismo y esquizofrenia. Valencia: PreTextos, 1988.

Ette, Ottmar. ZwischenWeltenSchreiben. Literaturen ohne festen Wohnsitz (ÜberLebenswissen t. 2). Berlin: Kadmos, 2005.

Kalscheuer, Britta y Lars Allolio-Näcke, eds. Kulturelle Differenzen begreifen. Das Konzept der Transdifferenz aus interdisziplinärer Sicht. Berlin: Campus, 2008.

Link, Daniel. "A César lo que es de César". Linkillo, Blog de Daniel Link 20 feb. 2007. <http://linkillo.blogspot.com/2007/02/al-csar-lo-que-es-del-csar.html>. 1 ago. 2014.

Ludmer, Josefina. "Literaturas postautónomas". CiberLetras 17 (2007). <http://www. lehman.cuny.edu/ciberletras/v17/ludmer.htm>. 1 ago. 2014.

Morales, Bruno. Bolivia construcciones: una novela. Buenos Aires: Sudamericana 2006. <http://lavaca.org/archivos/boliviaconstrucciones.pdf>.

Grandeza boliviana. Buenos Aires: Eterna Cadencia 2010.

Pacecca, María Inés y Corina Courtis. Inmigración contemporánea en Argentina: dinámicas y políticas. Santiago de Chile: Centro Latinoamericano y Caribeño de Demografía (CELADE) - División de Población de la CEPAL, 2008.

Santos, Susana. "La literatura interrumpida". Linkillo, blog de Daniel Link. 11 marzo 2007. <http://linkillo.blogspot.de/2007/03/literatura-interrumpida.html>. 1 ago. 2014.

Sarlo, Beatriz. La ciudad vista. Mercancías y cultura urbana. Buenos Aires: Siglo Venitiuno, 2009.

Speranza, Graciela. "Entrevista a DiNucci". Otra parte 12 (2007): s.p.

Spitta, Silvia. "La Virgen de Guadalupe (tan campante cruzando la frontera de mojada) y la llegada del mestizaje a los Estados Unidos". "El andar tierras", deseos y memorias. Homenaje a Dieter Ingenschay. Janett Reinstädler, Susanne Schlünder y Jenny Haase, eds. Madrid: Iberoamericana-Vervuert, 2008. 247-64.

Toro, Fernando de. "El desplazamiento de la literatura y las literaturas del desplazamiento y la problemática de la identidad". Extravio. Revista electrónica de literatura comparada 5 (2010): 8-30.

Zeiger, Claudio."The Bolivia Affair". Radar. Suplemento de Página 12. 28 marzo 2010.

Revista Iberoamericana, Vol. LXXXI, Núm. 253, Octubre-Diciembre 2015, 1065-1076 